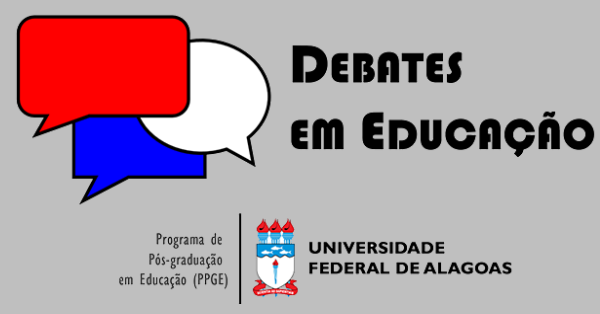

ISSN Eletrônico 2175-6600

Vol. 13 I Número Especial 2 I 2021

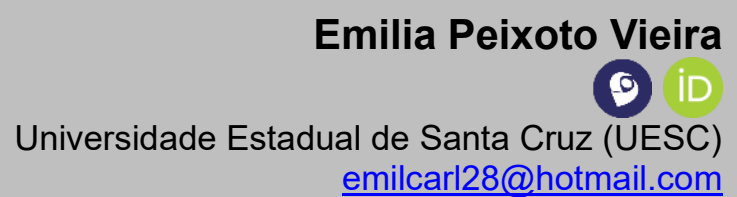

Andréia Ferreira da Silva

$\theta$ iD

Universidade Federal de Campina Grande

(UFCG)

silvaandreia@uol.com.br

Luciana Sedano

$\theta$ iD

Universidade Estadual de Santa Cruz (UESC) luciana.sedano@gmail.com

\section{ATUAÇÃO DO SETOR PRIVADO NA GESTÃO E ORGANIZAÇÃO DA EDUCAÇÃO INFANTIL EM MUNICÍPIOS NA REGIÃO SUL DA BAHIA}

\section{RESUMO}

O artigo analisa a atuação do setor privado na gestão e na organização da Educação Infantil em municípios do Sul da Bahia. O objetivo é compreender como tem sido a inserção de grupos empresariais nessa etapa da Educação Básica nesta região e os desdobramentos na Educação infantil. A investigação está fundamentada em uma abordagem crítica e dialética do objeto e, foram adotados os seguintes procedimentos metodológicos: revisão da bibliografia e análise de documentos federais e municípios que compõem a região estudada, bem como das empresas pesquisadas. Os resultados mostram que a celebração de parcerias entre o setor público e setor privado tem impactado na desestruturação do trabalho pedagógico desenvolvido nas instituições de educação infantil dos municípios situados na região Sul da Bahia.

Palavras-chave: Estado. Parcerias Público-Privada. Políticas Educacionais. Educação Infantil

PRIVATE SECTOR PERFORMANCE IN THE MANAGEMENT AND ORGANIZATION OF EARLY CHILDHOOD EDUCATION IN MUNICIPALITIES IN THE SOUTHERN REGION OF BAHIA

\section{ABSTRACT}

The article analyzes the role of the private sector in the management of Early Child Education in municipalities in the southern Bahia. The objective is to understand how the insertion of business groups in this stage of Basic Education in this region has been and the consequences in early childhood education. The investigation is based on a critical and dialectical approach to the object, and the following methodological procedures were adopted: bibliography review and analysis of federal and municipal documents that make up the studied region, as well as the companies surveyed. The results show that the celebration of partnerships between the public and private sector has impacted on the disruption of the pedagogical work developed in early childhood education institutions in the southern Bahia cities.

Keywords: State. Public-Private Partnerships. Educational Policies. Child Education.

Submetido em: 03/11/2020

Aceito em: 19/06/2021

Publicado em: 30/11/2021

do https://doi.org/10.28998/2175-6600.2021v13nEsp2p389-411

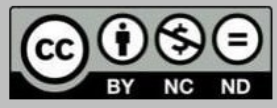

Esta obra está licenciada com uma Licença Creative Commons Atribuição-NãoComercial-SemDerivações 4.0 Internacional 


\section{INTRODUÇÃO}

Para compreender como tem sido a atuação do setor privado na gestão e na organização da Educação Infantil em municípios situados no Sul da Bahia é preciso compreender o processo de inserção de grupos empresariais nesta região e nesta etapa da Educação Básica. Tendo como referência a ampliação da atuação do setor empresarial no setor educacional e, especificamente, na Educação Infantil, foram formuladas as seguintes questões: Que tipos de parcerias são estabelecidos entre o setor público e o setor privado na Educação Infantil no Sul da Bahia? Quais desdobramentos tais parcerias têm produzido para a organização do trabalho pedagógico da Educação Infantil nesta região? Para responder tais questões, o artigo analisa as relações estabelecidas entre o setor público e o setor privado na primeira etapa da educação básica, em municípios situados no Sul da Bahia, e seus desdobramentos na gestão e na organização do trabalho pedagógico da Educação Infantil.

Para alcançar o objetivo proposto, examina o contexto histórico e político que propiciou a ampliação da atuação de empresas privadas na educação básica pública brasileira, a partir dos anos 1990, os institutos que realizaram parcerias com municípios do Sul da Bahia, com atuação na Educação Infantil, caracterizando as principais iniciativas desenvolvidas.

A pesquisa está fundamentada em ampla revisão bibliográfica e na análise de documentos. A revisão se debruçou sobre os estudos que analisam o fortalecimento da ideologia neoliberal e da terceira via no país e os processos de reforma do Estado e de privatização da Educação Básica, bem como a atuação de instituições e fundações empresariais na área de educação. A análise de documentos privilegiou o estudo de leis e normas referentes à legislação educacional federal e municipais e à regulamentação das "parcerias" entre o setor público e o setor privado. Também foram examinadas informações e relatórios disponíveis nos sites dos Institutos Natura e Arapyaú e blogs e jornais da região, buscando conhecer a organização e as áreas de sua atuação, bem como os projetos e os programas que desenvolvem na Educação Infantil na região Sul da Bahia.

O artigo objetiva, mais especificamente, conhecer os projetos realizados por esses institutos na Educação Infantil em municípios que integram a região Sul da Bahia, com destaque para a proposta de "reserva técnica" e as suas repercussões na gestão e na organização do trabalho pedagógico da Educação Infantil na região. 
Vale destacar, no entanto, que nossa compreensão sobre as "parcerias públicoprivada" na área da educação, na região investigada, está ancorada nas diferentes formas de privatização da educação assumidas no país a partir dos anos 1990. Segundo Adrião (2018), os processos de privatização no país vêm contemplando três dimensões: a gestão da educação, a oferta educacional e o currículo. Concentramos nosso foco de estudo na dimensão da gestão da educação, que segundo a autora, ocorre por meio da transferência da gestão escolar e/ou do sistema educacional público para organizações com fins lucrativos ou não, ou para cooperativas de trabalhadores ou pais, por meio de contratos de gestão/termos de parceria/acordo de colaboração (ADRIÃO, 2018).

Os processos de transferência da gestão educacional e escolar para setores privados assentam-se na possibilidade de introdução de sistemáticas de monitoramento sobre o trabalho pedagógico e sobre as atividades escolares tendo em vista a promessa de geração de informações para qualificar a tomada de decisão e a melhoria dos sistemas de ensino. As alternativas ofertadas envolvem a adoção de sistemas e plataformas digitais para a coleta e o gerenciamento de informações sobre desempenho de estudantes em testes de larga escala ou avaliações diversas; frequência de docentes e estudantes; a criação de esferas de gerenciamento e de modalidades de seleção de pessoal específicas para acompanhamento das medidas introduzidas; previsão de criação de banco de dados coletados junto aos sistemas de ensino e geridos pelo setor privado etc. (ADRIÃO, 2018)

O artigo está organizado em quatro partes. Na primeira, são discutidas as relações entre o setor público e o setor privado nas propostas do Neoliberalismo e da Terceira Via e o fortalecimento da atuação dos empresários no setor social e educacional, como uma das alternativas à "crise do Estado" e às novas configurações do Estado e da sociedade, desde as décadas finais do século XX. Em seguida, é analisado o processo de privatização da educação no país, vinculando-o à reforma do Estado, a partir dos anos de 1990. Na terceira parte, é examinada a atuação de duas empresas privadas, por meio de seus institutos, no setor educacional, mais precisamente, na Educação Infantil, na região Sul da Bahia e os desdobramentos dessa atuação para a organização do trabalho pedagógico nesta etapa da Educação Básica. O texto é concluído com as considerações finais. 


\section{NEOLIBERALISMO, TERCEIRA VIA E RELAÇÕES ENTRE O PÚBLICO E O PRIVADO: DESDOBRAMENTOS PARA O SETOR SOCIAL E EDUCACIONAL}

Os debates sobre as relações estabelecidas entre o setor público e o privado na educação brasileira marcam a história da educação no país, expressando-se, em cada contexto histórico, nas disputas entre diferentes projetos para a educação nacional. Neste texto, apresentamos as relações estabelecidas entre o setor público e o privado a partir dos anos 1990, no contexto de redefinição do Estado brasileiro e das políticas educacionais, inseridos em processos mais amplos de reordenamento das relações produtivas, de mundialização crescente do capital e de fortalecimento da ideologia Neoliberal no cenário internacional e nacional.

A atuação do Estado brasileiro, a partir dos anos finais da década de 1980, combinou proposições oriundas da defesa do direito à educação e da prioridade das políticas públicas educativas com ações e estratégias governamentais fundamentadas nas proposições do Neoliberalismo e da Terceira Via, pautadas na redução do papel do Estado na área econômica e nas políticas sociais. Em geral, tal combinação levou a processos de "distanciamento dos valores da gestão democrática e a prevalência da orientação empresarial nos sistemas de ensino" (PIRES, 2015, p. 49). Contraditoriamente, nesse contexto, ocorreu o reconhecimento legal da Educação Infantil como dever do Estado, direito da criança e primeira etapa da Educação Básica, por meio da aprovação da Constituição Federal de 1988 e da Lei de Diretrizes e Bases da Educação Nacional, Lei $n^{\circ}$ 9.394, de 21 de dezembro de $1996(1996)^{1}$.

Segundo Lima e Martins (2005, p. 44), a Terceira Via, vinculada, principalmente, às forças sociais de centro-esquerda, "parte das questões centrais do neoliberalismo para refiná-lo e torná-lo mais compatível com sua própria base e princípios constitutivos", consistindo em uma versão atualizada do projeto burguês que "mantém as premissas básicas do neoliberalismo em associação aos elementos centrais do reformismo socialdemocrata". Para Giddens (1999, p.36), formulador desse projeto, a Terceira Via

[...] se refere a uma estrutura de pensamento e de prática política que visa adaptar a socialdemocracia a um mundo que se transformou fundamentalmente ao longo das duas ou três últimas décadas. É uma terceira via no sentido de que é uma

\footnotetext{
${ }^{1}$ Tal reconhecimento resultou, entre outros, das lutas históricas de diversos segmentos da sociedade civil em defesa da creche pública, em especial de mães trabalhadoras, entidades acadêmicas, movimentos feministas, associações de mulheres, movimento negro, organizações de empregadas das empresas privadas e de órgãos públicos, entre outros (MACEDO, 2018), fortalecidos nos anos finais da ditadura civil-militar e da democratização da sociedade após 1985.
} 
tentativa de transcender tanto a socialdemocracia do velho estilo quanto o neoliberalismo.

Pelo exposto, a Terceira Via tem como objetivo a "reforma ou governo do capitalismo por intermédio de mudanças na política e na economia" (LIMA; MARTINS, 2005 , p. 44). O movimento revisionista proposto pela Terceira Via defende a reforma do Estado, incluindo um movimento de reeducação política das massas, com "a tentativa de compatibilizar a economia de mercado com justiça social” (MARTINS, 2006, p. 66), ou seja, implantar um capitalismo de "face humana" e um conformismo capaz de assegurar a coesão social (MARTINS, 2006).

No que se refere às políticas sociais, tanto o Neoliberalismo quanto a Terceira Via rejeitam a noção de direitos sociais, o princípio da universalidade e do financiamento público, defendendo estratégias de mercantilização e submissão dos bens sociais à lógica privada $^{2}$. Na implantação dessa visão, o Neoliberalismo defende processos, quase irrestritos, de privatização dos serviços sociais, e a Terceira Via propõe o estabelecimento de parcerias entre o Estado e a sociedade civil, mais especificamente, o chamado terceiro setor, para a oferta destes serviços, incluindo a educação ${ }^{3}$. Nessa compreensão, a denominada "sociedade civil ativa se tornaria o locus da ajuda mútua, da solidariedade, da colaboração e da harmonização das classes sociais" (LIMA; MARTINS, 2005, p. 53).

Para a Terceira Via, segundo Lima e Martins (2005), os novos organismos sociais estariam afastados das velhas organizações inspiradas na ideia de filantropia e das disputas que marcaram o "mundo das polaridades". Nessa perspectiva, ao "novo Estado democrático" caberia um papel educador da renovação da "cultura cívica" e de reordenamento da sociedade civil, incluindo novos marcos legais e normativas para a regulamentação das novas formas de relação entre Estado e sociedade. Para a materialização de tais mudanças, será necessária, de acordo com Giddens (1999), a disposição de a sociedade civil trabalhar em parceria com o Estado, o incentivo à autoorganização por grupos de interesses, o incentivo ao potencial das comunidades na

\footnotetext{
${ }^{2}$ De acordo com Lima e Martins (2005, p. 58), o argumento central do Neoliberalismo e da Terceira Via "é o de que se deve eliminar toda e qualquer política estatal que imobilize os indivíduos, gere obstáculos à expansão do mercado e crie dificuldades para o pacto entre capital e trabalho".

${ }^{3} \mathrm{De}$ acordo com Freitas (2018), as propostas apresentadas pelos neoliberais de privatização irrestrita da educação, por meio dos vouchers, e a proposta da terceirização de sua oferta, escolas charters, defendida por sociais-democráticos, de direita e esquerda, e pela Terceira Via de Antony Giddens, não são propostas diferentes, pois ambas propõem a privatização da educação. Para o autor, "a terceirização de escolas públicas para organizações sociais sem fins lucrativos não é uma alternativa à privatização, mas apenas um passo inicial" (p. 57), não sendo possível processos de "meia" privatização ou de "quase-mercado". As duas propostas conduziriam igualmente para a "destruição do sistema público de educação, por meio de sua conversão em uma organização empresarial inserida no livre mercado" (p. 56), objetivo último dos defensores do Neoliberalismo.
} 
resolução de seus próprios problemas e um pacto social para a solução pacífica dos conflitos sociais.

O "novo Estado democrático", proposto pela Terceira Via, deveria estimular o fortalecimento e a flexibilidade do mercado e, ao mesmo tempo, realizar as questões sociais por meio de mecanismos diferenciados dos defendidos pela socialdemocracia. Desse modo, "o 'Estado necessário' seria o regulador e coordenador de processos de desenvolvimento social e econômico capitalista. A ferramenta para a implementação dessa estratégia seriam as parcerias entre a esfera pública e a esfera privada" (MARTINS, 2006, p. 79). Nessa compreensão, a classe empresarial deveria se renovar politicamente, assumindo um "novo papel e uma nova conduta na sociedade civil, referenciada no postulado da 'responsabilidade social'" (MARTINS, 2009a, p. 82).

Assim, compreende-se que também deveriam ocorrer processos de fortalecimento de organizações comunitárias, mobilizadoras dos indivíduos para a superação dos problemas locais e para a redução da dependência da aparelhagem estatal, organizadas tendo como referência a noção de capital social ${ }^{4}$. Pelo exposto, deveriam ser fortalecidas iniciativas de empreendedorismo social e ações de voluntariado como estratégias para a constituição de uma "sociedade civil ativa" e a solução dos problemas sociais.

De acordo com Medeiros (2015), nesse contexto, os empresários passam a ser vistos, e se apresentam, como agentes centrais na resolução dos problemas sociais por meio da atuação de seus institutos e organizações na oferta de serviços sociais na área de educação, cultura e assistência social, entre outros. Dessa forma, a partir de meados da década de 1990, a noção de filantropia foi substituída pela de responsabilidade social.

Segundo Coutinho (2012, p. 2), a filantropia empresarial não é novidade no país, no entanto, é a partir do final da década de 1990, que "esse fenômeno toma maiores dimensões, sob a ideia de cidadania planetária [...]. Assim, a responsabilidade social empresarial amplia os espaços da participação individual ao campo jurídico-institucional de grupos particulares lucrativos".

A partir de então, de acordo com Pires (2015), a relação entre o setor público e o privado passou a ser fortalecida como estratégia para tornar a educação eficiente e eficaz e, ao mesmo tempo, contribuir para a reconfiguração do papel do Estado nessa área. Destaca-se, nesse processo, a atuação de institutos e fundações vinculados às empresas

\footnotetext{
${ }^{4}$ De acordo com Putnam (1996), capital social diz respeito à confiança, às normas e aos sistemas, característicos da organização social, que facilitam ações coordenadas e contribuem para aumentar a eficiência da sociedade. A noção de capital social tem sido utilizada para denominar a capacidade de articulação de grupos de pessoas ou de comunidades locais para solucionar os problemas imediatos, independente da intervenção do aparato estatal. Segundo Medeiros (2015), "a atuação/intervenção empresarial no campo social vem contribuindo para a disseminação e o fortalecimento do conceito de capital social" (p. 18).
} 
privadas no setor educacional, mediante projetos e programas direcionados às secretarias de educação e às escolas públicas nas áreas de gestão de sistemas escolares e de formação de professores.

Para Martins (2009b), a atuação empresarial no campo político e educacional não é algo novo, o que de fato é novo é a forma como essa classe dominante tem conseguido penetrar no seio da sociedade, por meio da criação de um organismo específico, para atuar na educação pública e com o discurso da educação de qualidade para todos. O autor constata "o protagonismo empresarial na definição dos rumos da educação no país e o discurso de que tal iniciativa refere-se a um projeto de nação em nome do bem comum exigem reflexões" (MARTINS, 2009b, p. 24).

Nessa perspectiva, os institutos e fundações vinculados às empresas privadas foram convertidos em atores centrais e apontados como qualificados para a condução do setor educacional, tanto no que se refere ao estabelecimento das diretrizes para o setor, quanto à sua própria gestão e oferta. O estabelecimento das "parcerias" entre o setor público e o setor privado, com a ampliação e a diversificação dos níveis, etapas e áreas de atuação e nas formas de contratação, se insere nesse processo de reforma do Estado, que, no Brasil, teve início na década de 1990. A seguir, é apresentado o processo inicial de organização da atuação dos empresários no setor educacional brasileiro, com destaque para o movimento Todos pela Educação.

\section{ATUAÇÃO DO EMPRESARIADO E AS POLÍTICAS EDUCACIONAIS}

A reforma do Estado brasileiro, evidenciada principalmente a partir dos anos de 1990, provocou mudanças nas ações do Estado junto à sociedade. O redesenho do Estado em suas formas de intervenção contribuiu significativamente para a reconfiguração da relação entre o público e o privado na gestão da educação. Para Oliveira (2009, p. 208), "adotam-se políticas que estabelecem nexo entre a elevação dos padrões de desempenho educativo e a crescente competitividade internacional, especialmente, através das parcerias público-privadas e contratos de gestão que trazem consequências para a democratização da educação". Novos atores, como o setor privado e o "público não estatal" se apresentam na sociedade e influenciam as agências governamentais que, em sua ação ambígua, contribuem para o avanço da mercantilização do setor (SANTOS; VIEIRA; SANTOS, 2017). 
De acordo com Adrião e Peroni (2009), as mudanças na atuação do Estado se revelaram, no âmbito da educação, como uma crescente tendência do Estado se retirar da execução, mas permanecer financiador e avaliador, deixando a responsabilidade em gerir o serviço para distintos agentes privados. Com o discurso de melhorar a qualidade da educação, o Estado transfere para a iniciativa privada, com a contratação de serviços, a gestão da educação, visando estratégias de resultados e elevação dos índices educacionais (SANTOS; VIEIRA; SANTOS, 2017).

De acordo com Peroni (2015), no Brasil, o processo de privatização do público vem ocorrendo por meio da direção das políticas, da sua execução ou de ambas as formas. No processo de direção, os empresários, seus movimentos, institutos e fundações, "acabam influenciando o governo federal, tanto na agenda educacional quanto na venda de produtos educativos" (PERONI, 2015, p. 28) e assessorias. Na execução, a privatização vem ocorrendo por meio de "políticas e/ou programas que ocorrem para as pessoas mais vulneráveis. A oferta, com algumas exceções, dá-se de forma precarizada, com bolsas ou salários simbólicos, em locais pouco apropriados, sem espaços democráticos de participação" (PERONI, 2015, p. 28-29).

Nos processos de privatização na direção e na execução da política, "instituições privadas definem o conteúdo da educação e executam sua proposta através da formação, avaliação do monitoramento, premiação e sanções que permitem o controle de que seu produto será executado" (PERONI, 2015, p. 29). Essas formas de privatização vêm redefinindo o papel do Estado em matéria de educação e contribuindo para a diversificação de iniciativas que são apresentadas, pelo setor privado, como "pacotes de qualidade" para a educação básica.

Exemplo de iniciativas privadas, o movimento Todos Pela Educação ${ }^{5}$ (TPE), formado por um conjunto de empresários, que a partir dos anos de 1990, se apresenta para discutir uma agenda educacional a fim de contribuir com o setor público. Em documentos, propõe reformar a educação e a escola, tornando-a mais eficaz para as novas demandas do capital, formando um novo trabalhador que domine as novas competências tecnológicas e organizacionais (BERNADI; UCZAK; ROSSI, 2015, p. 54).

\footnotetext{
${ }^{5}$ O Movimento Todos pela Educação (TPE), segundo Bernadi, Uczak, Rossi (2015, p. 54), teve início nos anos de 1990 , quando empresários brasileiros, por meio de fóruns, organizaram alguns documentos que salientavam a construção de uma agenda educacional, destacando a sociabilidade entre o setor público e o setor privado, que atendesse aos interesses do terceiro setor. A estrutura organizacional do Movimento é composta por um Conselho de Governança, com 18 integrantes presididos por Denise Aguiar Alvarez. Possui um Conselho Fiscal, com 3 integrantes, e uma Comissão Técnica, com 14 integrantes, coordenada por Viviane Senna (presidente do Instituto Ayrton Senna, que beneficia projetos para crianças em todo Brasil). Além de uma quantidade considerável de especialistas da área econômica, de comunicação e educação que são chamados de "sócios efetivos" e "sócios fundadores" (TPE). Disponível em: https://todospelaeducacao.org.br/, consulta realizada em 20 de novembro 2020.
} 
Conforme Martins (2009b), os empresários criaram o TPE com o intuito de "disputar e intervir" no campo educacional brasileiro, através de sua proposta de "contribuição" para a melhoria da qualidade da educação. Para que essa "missão" se cumpra, foi elaborado um projeto de ações denominado Compromisso Todos pela Educação. Este projeto foi apresentado em 2006, em um congresso com o título "Ações de responsabilidade social em educação: melhores práticas na América Latina", no qual "[...] foi possível apresentar e legitimar politicamente o projeto "Compromisso Todos pela Educação" e fortalecer no meio empresarial a importância de um organismo com capacidade para defender interesses da classe na sociedade civil e intervir na definição de políticas educacionais na aparelhagem do Estado" (MARTINS, 2009b, p. 23).

Conforme Martins (2009b, p. 23), analisando o papel dos empresários na perspectiva de Gramsci:

[...] o empresário representa uma elaboração social superior, já caracterizada por uma certa capacidade dirigente e técnica (isto é, intelectual): ele deve possuir uma certa capacidade técnica, não somente na esfera restrita de sua atividade e de sua iniciativa, mas também em outras esferas, pelo menos nas mais próximas da produção econômica (deve ser um organizador de massa de homens, deve ser um organizador da "confiança" dos que investem em sua empresa, dos compradores de sua mercadoria, etc.). Se não todos os empresários, pelo menos uma elite deles deve possuir a capacidade de organizar a sociedade em geral, em todo complexo organismo de serviço, até o organismo estatal, tendo em vista a necessidade de criar as condições mais favoráveis à expansão da própria classe; ou pelo menos, deve possuir a capacidade de escolher os "prepostos" (empregados especializados) a quem confiar esta atividade organizativa das relações gerais exteriores à empresa.

A ação do empresariado na educação demarca a disputa por uma hegemonia capaz de influenciar a sociedade, definir o papel do Estado em matéria de educação e imprimir formas de privatização que contribuem para a aproximação da sociedade ao mercado.

O Movimento, segundo Bernadi, Uczak, Rossi (2015, p. 59), propõe cinco metas com objetivos a serem alcançados até o ano de 2022. As metas, no entanto, não são exclusivamente do grupo. Conforme os autores, o TPE se "apropriam de demandas que historicamente estiveram pautadas pelo movimento de democratização da educação" e as reproduz como algo "inovador". As metas apresentadas, conforme publicadas no site são:

Meta 1 - Toda criança e jovem de 4 a 17 anos na escola.

Meta 2 - Toda criança plenamente alfabetizada até os 8 anos.

Meta 3 - Todo aluno com aprendizado adequado ao seu ano.

Meta 4 - Todo jovem com Ensino Médio concluído até os 19 anos;

Meta 5 - Investimento em Educação ampliado e bem gerido (TPE, 2016). 
A influência do empresariado, particularmente do TPE, na política educacional brasileira, na formação do professor, na gestão da escola, na forma como professores e alunos devem ser avaliados, como "garantia" de bons resultados, tem modificado a relação entre o setor público e o privado. Os projetos e os programas desenvolvidos partem do pressuposto de que a educação brasileira é ineficiente, então são necessárias intervenções de setores bem sucedidos como o setor privado para o seu desenvolvimento, desde a educação infantil até o ensino superior.

Segundo Martins (2006), a linha adotada pelo empresariado assemelha-se às interpretações do Banco Mundial (BM) nos anos de 1990, quando afirmava que os recursos para educação eram suficientes, mas o problema relacionava-se à falta de eficiência. O Banco Mundial, a partir dos anos de 1990, apresentou diversos documentos exaltando a parceria entre o setor público e o privado na educação, considerada como uma modalidade em expansão, e incentivou programas alternativos em substituição à educação escolar.

Rosemberg (2003, p. 7) destaca

[...] a entrada importante do Banco Mundial entre as organizações multilaterais que elaboram e divulgam modelos de política educacional, redefinindo prioridades e estratégias à luz dos conceitos de rede de proteção social e de focalização de políticas sociais para populações pobres.

Para a Educação Infantil, o BM recomenda que as "parcerias fora do setor público podem oferecer recursos significativos para expandir os serviços de desenvolvimento da primeira infância, melhorar sua qualidade e inovar para alcançar as populações mais carentes" (BANCO MUNDIAL, 2011, p. xix). De acordo com o BM,

[...] os municípios devem envolver o setor privado, a fim de adotar novas práticas que incrementem a qualidade dos serviços e também para poder explorar a possibilidade de contratação dos fornecedores do setor privado para atingir as populações mais necessitadas por meio de mecanismos inovadores. O MEC pode identificar e destacar exemplos das melhores práticas de parcerias públicoprivadas (BANCO MUNDIAL, 2011, p. 74).

Para Susin e Montano (2015), o Banco Mundial, em relatório "Programas para a geração mais importante do Brasil", publicado em 2011, aponta que as instituições privadas, de um modo geral, "têm maior qualidade (pelo menos em termos de infraestrutura e formação de professores)" (BANCO MUNDIAL, 2011, p. xii). Além disso, apresentam gastos "iguais ou inferiores" (p. 77) ao que o Estado aplica em educação.

As orientações do BM para a educação infantil, em sua maioria, assentadas em uma concepção de educação compensatória e de cunho assistencialista, reduzem o 
direito da criança pequena a uma "educação utilitarista", que busca atender as demandas do mercado de trabalho aliada ao combate à pobreza.

\section{A ATUAÇÃO DO SETOR PRIVADO NA EDUCAÇÃO INFANTIL EM MUNICÍPIOS DA REGIÃO SUL DA BAHIA}

Esta seção analisa as "parcerias" estabelecidas entre grupos empresariais e o setor público municipal, no Sul da Bahia, para a gestão da Educação Infantil e as repercussões dessas parcerias na organização do trabalho pedagógico na primeira etapa da educação básica.

No Sul da Bahia, dois institutos vinculados a empresas têm se dedicado a realizar "parcerias" com a gestão pública municipal no setor educacional: o Instituto Natura e o Instituto Arapyaú. Considerando a importância desses institutos, ancorados por empresas de repercussão na economia nacional e internacional, e o alcance das ações desenvolvidas no campo da educação, o presente artigo analisa suas iniciativas direcionadas à educação infantil.

\subsection{O Instituto Natura e o Instituto Arapyaú}

O Instituto Natura foi um dos primeiros a atuar na região. Foi fundado em 2010, com o intuito de expandir e fortalecer as iniciativas sociais da Natura já existentes desde 1995, voltadas à melhoria da qualidade da educação pública, de acordo com os pressupostos do Todos Pela Educação. No início, suas atividades estavam concentradas nos anos iniciais do Ensino Fundamental, dirigidos para as escolas e os gestores públicos e, em seguida, em iniciativas passaram a envolver, também, professores, pessoas e organizações que participam da educação na região.

O Instituto Natura está presente em todos os estados brasileiros e em mais de $80 \%$ dos municípios. Ele atua na articulação de ações e projetos: escola em tempo integral, comunidade de aprendizagem, escola digital, rede de apoio a educação, regime de colaboração entre União, estados e municípios e princípios de comunidade de aprendizagem incorporados nas práticas dos atores e das organizações da rede de educação (INSTITUTO NATURA, s. d.). Na Bahia, o Instituto está presente no desenvolvimento dos seguintes projetos: Comunidade de Aprendizagem; Conviva e o Projeto Trilhas no Sul da Bahia. 
Conta com atuação de 35 especialistas de natureza multidisciplinar - educação, comunicação e gestão em projetos - que ajudam a localizar os desafios e as oportunidades na área. Também dão suporte ao Conselho Fiscal, que discute e aprova os demonstrativos contábeis (INSTITUTO NATURA, s. d.).

O Instituto Natura, também, apoia iniciativas de diferentes organizações, "na colaboração e na construção coletiva de caminhos e soluções eficientes, trabalhando em parceria com diversas organizações da área educacional", como o Banco Interamericano de Desenvolvimento (BID), o Conselho Nacional de Secretários de Educação (CONSED), a União Nacional dos Dirigentes Municipais de Educação (UNDIME), a União Nacional dos Conselhos Municipais de Educação (UNCME), o Instituto Arapyaú (INSTITUTO NATURA, s. d.) e, na região Sul da Bahia, a Associação dos Municípios da Região Cacaueira da Bahia (Amurc).

Um espaço importante de atuação do Instituto Natura consiste na Rede de Apoio à Educação (RAE), destinada aos municípios, gestores e técnicos municipais da educação, que "integra iniciativas e comunidades para implementação de políticas educacionais, potencializando compromissos e resultados, além de incentivar ações colaborativas entre os municípios" (INSTITUTO NATURA, s. d.). O projeto é realizado de duas formas conforme explica o Instituto:

RAE Plena: contribui para a gestão educacional e o aprendizado dos alunos. Acontece em Benevides (PA) e Cajamar (SP), onde a Natura tem operações. Atuação customizada do Instituto Natura, com base nas necessidades locais e na análise do diagnóstico desenvolvido pelo Instituto Natura.

RAE Polos: apoio à gestão municipal e implementação de projetos educacionais em grupos de municípios (polos) com desafios semelhantes na educação. Acontece em 86 municípios (polos Bahia, Nordeste Paraense e Sudeste), tendo como foco a gestão pública colaborativa (INSTITUTO NATURA, s. d.).

Em 2015, o Instituto Natura iniciou sua atuação no Polo Sul Bahia, por meio de seu projeto Rede de Apoio à Educação (RAE Polos), em articulação com o Instituto Arapyaú, a Associação dos Municípios da Região Cacaueira da Bahia (Amurc) e a Universidade Estadual de Santa Cruz (UESC).

O Instituto Arapyaú é uma instituição privada, sem fins lucrativos, que tem por objetivo fortalecer redes, organizações e projetos que atuam na promoção da sustentabilidade. Foi criado em 2008, inspirado na crença de que a filantropia pode ser uma força para o bem-estar social, ambiental e econômico. Faz parte de um grupo de empresas, como a Natura, Itaú, organizações sem fins lucrativos e de investimento de impacto que têm como essência o compromisso com a sustentabilidade em todas as suas dimensões (ARAPYAÚ, 2019). 
Propõe-se a oferecer apoio estratégico, financeiro e de articulação a iniciativas alinhadas em três programas prioritários de apoio, principalmente para a região do Sul da Bahia: 1. Desenvolvimento Territorial do Sul da Bahia (DTSB); 2. Mudanças Climáticas e Cidades; e 3. Territórios.

O Programa Desenvolvimento Territorial do Sul da Bahia (DTSB), direcionado à educação, visa contribuir para melhorar a aprendizagem dos alunos, a formação dos professores e a gestão dos recursos das secretarias de educação nos municípios da Costa do Cacau. Esse programa foi desenvolvido a partir de 2015, como projeto-piloto, em parceria com as prefeituras de Uruçuca e Uma (ARAPYAÚ, 2019).

O Instituto Arapyaú tem atuado como parceiro direto do Instituto Natura na condução de suas iniciativas na região Sul da Bahia para o setor educacional. Em atuação conjunta, os institutos coordenaram a realização, em 2015, do Encontro de fortalecimento do Consórcio de Desenvolvimento Sustentável do Litoral Sul (CDS-LS). O CDS-LS foi criando pela Associação dos Municípios da Região Cacaueira da Bahia (AMURC), no ano de 2015, com área de atuação em 16 municípios do Sul da Bahia, visando atender as demandas dos municípios consorciados, através da escala proporcionada pelo consórcio (AMURC, 2019).

Neste mesmo ano, o Instituto Natura e o Instituto Arapyaú estiveram à frente das discussões em outros encontros do CDS-LS, que contaram com a participação de técnicos da educação, secretários de educação e prefeitos. Tais reuniões tiveram como objetivos, dentre outros, auxiliar os municípios na revisão do Plano de Cargo Carreira e Remuneração (PCCR) e na implantação da jornada de trabalho do professor da educação básica referente a 1/3 da carga-horária sem interação com os alunos, estabelecida na Lei n. ${ }^{\circ}$ Lei $n^{\circ} 11.738$, de 16 de julho de 2008, que instituiu o Piso Salarial Profissional Nacional para os profissionais do magistério público da educação básica. Como resultados desses encontros foram apresentadas propostas de reformulação ou de aprovação de PCCR, que foram aprovados e implantados em municípios da região.

A capacidade de articulação do Instituto Natura, por meio de seu projeto Rede de Apoio à Educação (RAE Polos), em mobilizar vários representantes municipais, pode ser percebida na mobilização para a realização do I Encontro de Formação da Rede de Apoio à Educação - Polo Bahia, em maio de 2015. O gerente do programa na Bahia, Ricardo Gomes, relata sobre o evento:

O I Encontro de Formação da Rede de Apoio à Educação - RAE do polo Bahia contou com 80 técnicos educacionais e com 36 dirigentes municipais de educação, dos 36 municípios das regiões Sul, Baixo Sul e Sudoeste da Bahia, integrantes e convidados da Associação dos Municípios do Sul, Extremo Sul e 
Sudoeste Baiano - AMURC. Além deles, estiveram presentes representantes da Universidade Estadual de Santa Cruz - UESC, da AMURC, da União Nacional dos Dirigentes Municipais de Educação - UNDIME e da Fundação Lemann. [...]. O encontro teve como objetivo apresentar os projetos Trilhas, Comunidade de Aprendizagem, Escola Digital, Plano Municipal de Educação, Conviva Educação e Plano de Cargo Carreira e Remuneração. Houve também assessoria para a elaboração e inserção do Plano Municipal de Educação - PME na plataforma Conviva Educação (INSTITUTO NATURA, s. d.).

No mesmo ano, no mês de outubro, o Instituto realizou o III Encontro Nacional da Rede de Apoio à Educação (RAE), no Rio de Janeiro, inaugurando sua atuação nos polos Sudeste (interior de São Paulo) e reafirmando a participação no Sul da Bahia. O objetivo foi integrar municípios e atores da educação em uma rede que incentivasse ações colaborativas que levassem a melhores práticas de gestão nos sistemas públicos de educação.

O ano de 2015 foi muito significativo na atuação do Instituto Natura e do Instituto Arapyaú na região Sul da Bahia. Vários municípios realizaram a revisão de seus Planos de Cargo Carreira e Remuneração (PCCR), a partir do assessoramento desses institutos. Além disso, em diversos encontros com gestores municipais, técnicos da educação, professores foi discutida a implantação de $1 / 3$ da jornada de trabalho docente na educação, referente à carga-horária com contato com os alunos, denominada pelos institutos como "reserva técnica"6. O município de Una/BA foi o primeiro da região em estudo a implantar a "reserva técnica" para os(as) docentes ${ }^{7}$ da Educação Infantil, com a assessoria firmada com o Instituto Arapyaú, ainda em 2015.

O acordo de cooperação, com apoio técnico e consultivo, entre os institutos e a gestão municipal, como o município de Una/BA, por exemplo, demonstra a disposição e a estratégia dessas empresas, com o discurso da responsabilidade social, em imprimir uma educação eficiente e eficaz pautada no incentivo ao potencial das comunidades (professores, técnicos da secretaria de educação, famílias das crianças, comunidade em geral) na resolução de seus próprios problemas, estabelecendo parcerias entre a esfera pública e a esfera privada, para a gestão da educação.

\footnotetext{
${ }^{6}$ Pesquisamos em diversas fontes para compreender o motivo dos Institutos denominarem o $1 / 3$ da jornada de trabalho docente, sem o contato com os alunos, de "reserva técnica" e não encontramos nenhuma razão. A Lei n 11.738/2008 instituiu o piso salarial profissional nacional para os profissionais do magistério público da educação básica e estabeleceu, no $\S 4^{\circ}$, do art. $2^{\circ}$, que na composição da jornada de trabalho: "[...] observar-se-á o limite de $2 / 3$ (dois terços) da carga horária para o desempenho das atividades de interação com os educandos"(BRASIL, 2008) e que, no mínimo, 1/3 (um terço) da jornada de trabalho deverá será destinada às atividades sem contato com os alunos, compreendidas como preparação de aulas, planejamento pedagógico, avaliação da produção de alunos, reuniões escolares, contatos com a comunidade e formação continuada (BRASIL, Parecer CNE/CEB18/2012).

${ }^{7}$ Compreendemos como docentes (gestoras, coordenadoras e professoras). Utilizamos a indicação do gênero, indicando que na região, assim como no país, de modo geral, o quantitativo maior é de mulheres em atuação na educação infantil.
} 
No início de 2016, o Instituto Natura realizou, em parceria com o Instituto Arapyaú e a Amurc, um encontro com os municípios do Sul da Bahia para tratar do regime de colaboração entre secretarias municipais de educação de 36 municípios do Estado. $O$ objetivo do encontro foi "fortalecer a colaboração horizontal entre secretarias municipais de educação e vertical entre município, estado e União - Ministério da Educação (MEC) para soluções de desafios comuns; implementação de Metas dos Planos Municipais de Educação elaborados em 2015, com assessoria da parceria da RAE" (INSTITUTO NATURA, s. d.).

Em 2017, o Instituto Natura, por meio da Rede de Apoio à Educação, articulou-se com dois consórcios públicos municipais, um com os municípios situados no Sul da Bahia, por meio da Amurc, o Consórcio de Desenvolvimento Sustentável Litoral Sul (CDS-LS, e outro com municípios do extremo Sul da Bahia, organizados na CIAPRA - Baixo Sul ${ }^{8}$, com o objetivo da instalação de Câmara Técnica de Educação ${ }^{9}$, visando o apoio efetivo às secretarias de educação em suas ações educacionais.

Em 2018, foram realizadas algumas reuniões de planejamento, promovidas pelo Instituto Natura e o Instituto Arapyaú, como a ocorrida entre os municípios do litoral Sul da Bahia, em junho, para o aprofundamento do "debate sobre a política de reserva técnica, que trata do período que os educadores devem destinar ao planejamento e à formação" (Instituto Natura, s. d.) ${ }^{10}$. Os participantes também discutiram os avanços no funcionamento da Câmara Técnica de Educação nessa região.

Em relação à implantação da "reserva técnica", os municípios do Sul da Bahia, pressionados a cumprir o previsto na Lei n. ${ }^{0} 11.738$, de 16 de julho de 2008 , que institui o piso salarial profissional nacional para os profissionais do magistério público da educação básica, recorreram à "parceria" com o Instituto Natura e o Instituto Arapyaú para buscar alternativas para a viabilização desta política, principalmente para os(as) docentes da Educação Infantil. Desse modo, os institutos participaram efetivamente na elaboração do plano de ação para implantação da "reserva técnica". Segundo o Instituto Natura, sua

\footnotetext{
${ }^{8}$ O consórcio CIAPRA BAIXO SUL foi fundado, em 2008, pelos municípios de: Ibirapitanga, Pirai do Norte, Ituberá, Igrapiúna e Nilo Peçanha. No ano de 2014, passaram a integrar o consórcio os municípios de: Camamu, Cairu, Taperoá, Valença, Gandu, Teolandia, Wensaelau Guimarães e Presidente Tancredo Neves (CIAPRA, s. d.).

${ }^{9} \mathrm{~A}$ institucionalização da Câmara Técnica de Educação (CTE) do Consórcio CDS-LS, visa "[...] buscar desenvolver atividades educacionais que atendam às necessidades dos municípios consorciados de acordo com suas realidades" (REDE DE COLABORAÇÃO INTERMUNICIPAL EM EDUCAÇÃO, 2019, s. p.). As Câmaras Técnicas de Educação são espaços institucionalizados dentro dos consórcios Intermunicipais, nas quais os gestores de educação dos municípios participantes se reúnem para desenvolver ações cooperadas. [...]. Visa, entre outros, estimular "a união de forças para a criação de ações que potencializem os recursos existentes e transformem a educação pública regional" (INSTITUTO UNIBANCO, s. d.).

10 O evento contou com o apoio da Amurc e do Consórcio de Desenvolvimento Sustentável Litoral Sul (CDS-LS), além da participação da Pró-Reitoria de Extensão da UESC, da Câmara Técnica de Educação do Consórcio Intermunicipal de Gestão Pública Integrada nos Municípios do Baixo Paraíba (COGIVA), da Oficina Municipal e do Instituto Arapyaú.
} 
atuação visou contribuir para os municípios criassem "condições favoráveis para que os professores da rede conseguissem cumprir $1 / 3$ da jornada fora da sala de aula de maneira adequada" (INSTITUTO NATURA, s. d.).

A atuação dos Institutos Natura e Arapyaú na gestão da educação pública municipal na região Sul da Bahia, apresentando soluções à educação da região, "apoiados em estudos"11, influenciou o município de llhéus na regulamentação do 1/3 da jornada, em atividades extraclasse, dos(as) docentes em exercício na Educação Infantil, com a implantação da "reserva técnica". Desde 2018, o município alterou a organização da jornada de trabalho dos(as) professores(as) da Educação Infantil ${ }^{12}$, redefinindo a organização do trabalho pedagógico e a disposição dos horários de permanência dos professores com as crianças.

Desse modo, de acordo com as diretrizes para implantação da Reserva Técnica, especialmente para a Educação Infantil do município, a carga horária semanal dos(as) professores(as) deve obedecer a seguinte distribuição: 13 horas/aulas, sem o contato com as crianças, para professores(as) com contrato de 20 horas; e 26 horas/aulas para professores(as) com contrato de 40 horas (ILHÉUS, 2018). Para o cumprimento desta organização, cada professora exerce as atividades com as crianças em dois dias e meio, de uma jornada semanal de cinco dias, em um sistema de escala ${ }^{13}$.

Pelo exposto, de acordo com as Diretrizes (2018), a carga-horária semanal, referente ao $1 / 3$ da jornada de trabalho, deverá ser cumprida de forma coletiva por escola e assim distribuída:

[...] de terça a quinta-feira, conforme escala a ser elaborada pela SEDUC num total de $5 \mathrm{~h}$ aulas para professores de $40 \mathrm{~h}$ e $2 \mathrm{~h} / 30$ para professores de $20 \mathrm{~h}$. As demais horas que os professores não estiverem em aula ou planejamento coletivo serão destinadas as atividades complementares (confecção de material, preenchimento de registros, organização de atividades e outras atividades definidas no planejamento), participação em formação com a Rede, a ser definido e convocado pela Secretaria de Educação, quando necessário (ILHÉUS, 2018, p. 24).

Desse modo, a Secretaria Municipal de Educação definiu que o planejamento coletivo será realizado de terça a quinta-feira com a participação, além dos dois(duas)

\footnotetext{
11 Os sites dos Institutos Natura e Arapyaú afirmam que, antes de auxiliar a gestão municipal, realizam um estudo diagnóstico da situação dos municípios. Em nossas pesquisas não encontramos esses estudos e os dados desse diagnóstico.

${ }^{12}$ Essa alteração, contudo, não fez com que o município cumprisse a Lei do Piso. O município, até 2017, não pagava o piso a todos os professores. A gestão municipal, que assumiu no ano de 2017, negociou e parcelou o pagamento do piso para os professores de sua rede de ensino.

${ }^{13}$ As mudanças na jornada do trabalho docente, para o cumprimento da carga-horária de $1 / 3$ fora da sala de aula, sem o cumprimento da remuneração adequada, passou a ser denominada, por vários professores(as) e gestores(as), como "folga", revelando que o tempo extraclasse, disponibilizado para a realização do planejamento, estudo e produção de materiais, entre outras atividades, pode não estar sendo usado adequadamente.
} 
professores(as) de referência da turma, de mais um(a) professor(a) "rotativo"14, responsável pelas "disciplinas diversificadas", e um(a) professor(a) de apoio, conforme consta nas Diretrizes para a Educação Infantil:

Para a realização da AC [Atividade Complementar - conhecida como de planejamento] Coletivo haverá um grupo de professores que atuará de forma rotativa com os conteúdos das disciplinas diversificadas. Este grupo planejará coletivamente as segundas-feiras com a Coordenação de Educação Infantil, atividades para aplicação baseadas na Matriz Curricular. Haverá ainda um professor de apoio a cada 2 (duas) turmas e dois professores de apoio a cada 5 (cinco) turmas, podendo ser aproveitados os regentes em readaptação funcional. Os professores de apoio realizarão seu planejamento na escola com o supervisor escolar no dia que os dois regentes estiverem na sala de aula juntos. São funções do professor de apoio de forma ampla, apoiar o professor regente no desenvolvimento de atividades de ensino e de aprendizagem, em especial, nas ações relacionadas ao educar/cuidar e ao brincar, oferecidas simultaneamente aos alunos ao longo da carga horária semanal (ILHÉUS, 2018, p. 24, grifos nossos).

Em relação às diretrizes, acima, podem ser destacadas algumas questões. A primeira consiste na utilização do termo "disciplinas diversificadas" que pode ser visto como uma forma direta de disciplinar a Educação Infantil o que é contrário ao disposto nas Diretrizes Curriculares Nacionais para a Educação Infantil (DCNEI), de 2009, que no seu artigo $9^{\circ}$ propõe que a prática pedagógica para a Educação Infantil tenha como eixo estruturante do currículo as interações e a brincadeira, desse modo, as práticas educacionais estão organizadas em torno do conhecimento e não em disciplinas. De acordo com a DCNEI (2009), o currículo da Educação Infantil deve ser concebido como "um conjunto de práticas que buscam articular as experiências e os saberes das crianças com os conhecimentos que fazem parte do patrimônio cultural, artístico, científico e tecnológico" (BRASIL, 2009).

A segunda questão diz respeito ao fato de que a organização das diretrizes divide o planejamento das atividades pedagógicas a serem devolvidas nas turmas de Educação Infantil: por um lado, o planejamento a ser realizado, na escola, pelos(as) professores(as) de referência da turma e, por outro, o planejamento a ser feito pelo(a) professor(a) "rotativo" e o(a) professor(a) de apoio com a Coordenação de Educação Infantil, na segunda-feira, na Secretaria Municipal de Educação de Ilhéus acerca dos conteúdos das disciplinas diversificadas. Essa prática contradiz o próprio documento quando define que

\footnotetext{
14 Em relação ao professor "rotativo", a Proposta Curricular, define que "Para a realização do AC [Atividade Complementar - conhecida como de planejamento] Coletivo haverá um grupo de professores(as) que atuará de forma rotativa com os conteúdos das disciplinas diversificadas. Este grupo planejará coletivamente as segundas-feiras com a Coordenação de Educação Infantil, atividades para aplicação baseadas na Matriz Curricular (ILHÉUS, 2018, p. 25).
} 
o planejamento necessita ser elaborado coletivamente e que o(a) professor(a) de apoio deve apoiar "de forma ampla" o(a) professor(a) referência de cada turma.

Na prática, a organização do trabalho pedagógico a ser executado com as crianças pelo(a) professor(a) a atuar na disciplina diversificada é feita pela Secretaria de Educação, o que gera uma contradição em relação a pensar um trabalho coletivo. Além do exposto, os(as) professores(as) de referência não atuam, em sala de aula, em conjunto com o(a) professor(a) "rotativo" e o(o) professor(a) de apoio, visto que quando os(as) professores(as) de referência da turma estiverem em planejamento coletivo, tais profissionais estarão assumindo a regência da sala de aula, impossibilitando-os de ter contato com os(as) professores(as) de referência da turma para conhecimento maior das crianças e das atividades desenvolvidas.

Quanto à distribuição da carga horária dos(as) professores(as), no documento são apresentadas quatro propostas, vejamos dois exemplos, conforme Quadro 1 e Quadro 2:

Quadro 1. Proposta de Distribuição da Carga Horária de Professores Setor 1 Planejamento coletivo às terças, conforme Proposta Curricular Pedagógica para a

Educação Infantil do município de Ilhéus/BA (2018)

\begin{tabular}{|cccccc|}
\hline Aulas & Segunda & Terça & Quarta & Quinta & Sexta \\
\hline $1^{\text {a }}$ aula & P1*/P2** & *Div. & P1 & P1 & P2 \\
$2^{\text {a }}$ aula & P1/P2 & Div. & P1 & P1 & P2 \\
$3^{\text {a } \text { aula }}$ & P1/P2 & Div. & P1/P2 & P1 & P2 \\
$4^{\text {a }}$ aula & P1/P2 & Div. & P2 & P1 & P2 \\
$5^{\text {a }}$ aula & P1/P2 & Div. & P2 & P1 & P2 \\
\hline
\end{tabular}

Fonte: Proposta Curricular Pedagógica para a Educação Infantil do município de Ilhéus/BA (2018) ${ }^{*} \mathrm{P} 1$ - Professor referência da turma e ${ }^{* *} \mathrm{P} 2$ - Professor referência da turma. *Div. - Diversificada.

Quadro 2. Proposta de Distribuição da Carga Horária de Professores Grupo 4 Planejamento coletivo às sextas, conforme Proposta Curricular Pedagógica para a Educação Infantil do município de Ilhéus/BA (2018)

\begin{tabular}{|lccccc|}
\hline \multicolumn{1}{|c}{ Aulas } & Segunda & Terça & Quarta & Quinta & Sexta \\
\hline $1^{\mathrm{a}}$ aula & $\mathrm{P} 1^{*}$ & $\mathrm{P} 2^{* *}$ & $\mathrm{P} 1$ & $\mathrm{P} 1 / \mathrm{P} 2$ & ${ }^{*}$ Div. \\
$2^{\mathrm{a}}$ aula & $\mathrm{P} 1$ & $\mathrm{P} 2$ & $\mathrm{P} 1$ & $\mathrm{P} 1 / \mathrm{P} 2$ & Div. \\
$3^{\mathrm{a}}$ aula & $\mathrm{P} 1$ & $\mathrm{P} 2$ & $\mathrm{P} 1 / \mathrm{P} 2$ & $\mathrm{P} 1 / \mathrm{P} 2$ & Div. \\
$4^{\mathrm{a}}$ aula & $\mathrm{P} 1$ & $\mathrm{P} 2$ & $\mathrm{P} 2$ & $\mathrm{P} 1 / \mathrm{P} 2$ & Div. \\
$5^{\mathrm{a}}$ aula & $\mathrm{P} 1$ & $\mathrm{P} 2$ & $\mathrm{P} 2$ & $\mathrm{P} 1 / \mathrm{P} 2$ & Div. \\
\hline
\end{tabular}

Fonte: Proposta Curricular Pedagógica para a Educação Infantil do município de llhéus/BA, de 2018. ${ }^{*} \mathrm{P} 1$ - Professor referência da turma e ${ }^{* *} \mathrm{P} 2$ - Professor referência da turma. *Div. - Diversificada.

Nos dois exemplos, expostos nos Quadros 1 e 2, um dia da semana não há a presença de professores(as) referência na turma da Educação Infantil. Cada professor(a) tem assumido apenas uma parte da jornada semanal com as crianças, ficando os demais dias a cargo do(a) segundo(a) professor(a) referência da turma e do(a) professor(a) 
"rotativo", responsável pelas disciplinas diversificadas. O(A) professor(a) da parte diversificada, para preencher sua carga horária deve atuar em, pelo menos, quatro instituições diferentes.

Vale ressaltar que, no rearranjo da gestão municipal para o cumprimento do $1 / 3$ da carga-horária dos(as) professores(as) para atividades extraclasse, a Secretaria Municipal de Educação de llhéus vem realizando a contratação de estagiários(as) do curso de Pedagogia para assumirem as turmas de Educação Infantil quando os(as) professores(as) não estão presentes. De acordo com a Resolução do CME n. ${ }^{\circ} 3 / 2018$, "Os estagiários de Pedagogia (Educação Infantil) [...] aplicarão projetos coordenados pela Seduc para garantir o tempo de planejamento pedagógico" (ILHÉUS, 2018, art. $7^{\circ}$, § $3^{\circ}$ ). Tal prática reforça processos de precarização e de flexibilização do trabalho docente quando utiliza estudantes de Pedagogia, às vezes do segundo período, sem formação para atuarem como docentes regentes das turmas. Os(As) estagiários(as) não contam com acompanhamento nas atividades realizadas com as crianças. Essas práticas não contribuem para uma formação inicial adequada e consistente dos(as) discentes de Pedagogia, e o curioso, respaldadas pelo CME.

Observa-se que a organização do trabalho dos(as) professores(as) na Educação Infantil no município de llhéus, que se funda no revezamento de profissionais nas turmas, professores(as) de referência, professor(a) "rotativo", professor(a) de apoio e estagiário(a), vem gerando indefinição e insegurança entre as crianças pequenas e suas famílias, ampliando as dificuldades para o estabelecimento de vínculos com os(as) professores(as) de referência da turma. A construção de referenciais para as relações entre adultos e crianças nas turmas da Educação Infantil, que envolve a construção de vínculos de confiança e a criação de rotinas relativas aos processos de cuidado e de educação, tão importantes para essa etapa do desenvolvimento infantil, com esse rearranjo, fica ameaçada ${ }^{15}$.

Outros municípios do Sul da Bahia, como Ubaitaba e Uruçuca, estudam, com apoio desses Institutos, formas de implantar a "reserva técnica" na Educação Infantil, em suas redes de ensino.

\footnotetext{
15 Há ainda, situações, relatadas por professores(as), em que no dia dos conteúdos da parte diversificada, sob a responsabilidade dos(as) estagiários(as), algumas famílias não enviam suas crianças para a instituição, pois, sabem que o trabalho não tem a mesma sequência desenvolvida pelos(as) professores(as) referências da turma. Essa situação tem levado a fragmentação nas rotinas da escola e a descontinuidade do trabalho pedagógico desenvolvido com as crianças, visto que a articulação das atividades propostas nem sempre é possível.
} 


\section{CONSIDERAÇÕES FINAIS}

A estratégia de "parcerias" tem se intensificado após os anos de 1990 e, atualmente, existem empresas oferecendo projetos de intervenção em todos os níveis e modalidades da educação. Em relação à Educação Infantil, as parcerias concentram-se na gestão educacional, na gestão pedagógica, na organização do trabalho pedagógico, no currículo, na política de carreira dos docentes e na formação de professores.

Outro ponto observado são as justificativas encontradas para que estes Institutos atuem na educação. Eles se apropriam dos discursos historicamente reivindicados pelos movimentos sociais em defesa da democratização da educação e apresentam da forma que eles acreditam ser a mais eficaz. No entanto, todo esse movimento de empresas em favor da melhoria da educação pública brasileira está respaldado nas estratégias neoliberais para o século XXI, que alguns autores nomeiam de "Terceira Via". Estratégias essas que tentam a todo o momento (re)formular e (re)definir o significado de política pública na garantia do direito à educação para todos, e no papel do Estado a gerir essa educação.

O Instituto Natura, com o apoio do Instituto Arapyaú e o convênio estabelecido com a Amurc e o CDS-LS, aproximaram-se da gestão pública da educação municipal do Sul da Bahia, alterando a relação entre o setor público e privado, em que ao Estado (representado pelo município) cabe tomar providências para execução do projeto proposto pelos Institutos, de "pacotes de qualidade" para a educação básica.

O artigo, ao analisar as relações estabelecidas entre o setor público e o setor privado na Educação Infantil, em municípios situados no Sul da Bahia, apontou desdobramentos relativos à implantação de importantes mudanças na organização do trabalho pedagógico da Educação Infantil. Pelo exposto, sobre a proposta implantada no município de llhéus, os Institutos estudados vêm atuando, junto à gestão de redes municipais de ensino, com orientações que se contrapõem aos princípios estabelecidos nas DCNEI (2009), contribuindo para processos de padronização de educação e de fragmentação nos processos formativos na primeira etapa da Educação Básica, o que evidencia sua capacidade a alcançar os diferentes atores da educação: crianças, professores(as), gestores municipais e a comunidade, apesar dos limites e incoerência de suas propostas.

Por meio desta pesquisa, evidenciamos as estratégias dos agentes empresariais, que, na arena da política educacional, vêm influenciando gradativamente a gestão pública 
municipal acerca da Educação Infantil com argumentos e práticas pautadas na eficiência e na eficácia, termos do mercado. É importante o resgate da escola pública como direito de todos e a legitimação da política pública de educação como dever do Estado.

\section{REFERÊNCIAS}

ADRIÃO, Theresa. Dimensões e formas da privatização da educação no Brasil: caracterização a partir de mapeamento de produções nacionais e internacionais. Currículo sem Fronteiras, v. 18, p. 8-28, 2018. (online). Disponível em:

http://www.curriculosemfronteiras.org/vol18iss1articles/adriao.pdf. Acesso em: 8 mar. 2019.

ADRIÃO, Theresa; PERONI, Vera. A educação pública e sua relação com o setor privado: implicações para a democracia educacional. Revista Retratos da Escola, v. 3, n. 4, p. 107-116, 2009. Disponível em:<http://esforce.or.br>. Acesso em: 5 abr. 2018.

BANCO MUNDIAL. Educação infantil: programas para a geração mais importante do Brasil. 2011. Disponível em:

<http://documents.worldbank.org/curated/en/437551468226169400/pdf/693070PORTUGE Solmportante0do0Brasil.pdf>. Acesso em: 3 maio 2019.

BERNARDI, Liane Maria; UCZAK, Lucia Hugo; ROSSI, Alexandre. As relações do Estado com empresários nas políticas educacionais: PDE/PAR e guia de tecnologias educacionais. In: PERONI, Vera (org.). Diálogos sobre definições no papel do Estado e nas fronteiras entre o público e o privado na educação. São Leopoldo: Oikos, 2015, p.52-71.

BRASIL. Ministério da Educação. Diretrizes Curriculares Nacionais para a Educação Infantil/DCNEI. Parecer CNE/CEB, ${ }^{\circ}{ }^{20 / 2009}$. Secretaria de Educação Básica. Brasília: MEC, SEB, 2010. Disponível em:

<http://portal.mec.gov.br/dmdocuments/pceb020_09.pdf>. Acesso em 22 set. 2017.

BRASIL. Lei no 11.738, de 16 de julho de 2008. Regulamenta a alínea "e" do inciso III do caput do art. 60 do Ato das Disposições Constitucionais Transitórias, para instituir o piso salarial profissional nacional para os profissionais do magistério público da educação básica. Disponível em: <http://www.planalto.gov.br/ccivil_03/_ato20072010/2008/lei//11738.htm>. Acesso em 5 set. 2017.

BRASIL. Decreto $n^{\circ}$ 6.094, 24 de abril de 2007. Dispõe sobre a implementação do Plano de Metas Compromisso Todos Pela Educação, pela União Federal, em regime de colaboração com Municípios, Distrito Federal e Estados, e participação das famílias e da comunidade, mediante programas e ações de assistência técnica e financeira, visando a mobilização social pela melhoria da qualidade da educação básica.Disponível em:<http://www.planalto.gov.br/ccivil_03/_Ato2007-2010/2007/Decreto/D6094.htm>. Acesso em: 09 set. 2020. 
BRASIL. Lei no 10.172, de 09 de janeiro de 2001. Aprova o Plano Nacional de Educação PNE e dá outras providências. Presidência da República, Ministério da Educação/MEC, 2001. Disponível em: <http://www.planalto.gov.br/ccivil_03/leis/leis_2001/l10172.htm>. Acesso em: 21 set. 2020.

BRASIL. Presidência da República. Casa Civil. Lei n 9.394/96, de 20 de dezembro de 1996. Estabelece as diretrizes e base da educação nacional. Disponível em:

<http://www.planalto.gov.br/ccivil_03/Leis/L9393.htm>. Acesso em: 10 set. 2017.

BRASIL. Constituição da República Federativa do Brasil de 1988. Presidência da República, Casa Civil, 1988. Disponível em:

<http://www.planalto.gov.br/ccivil_03/constituicao/constituicaocompilado.htm>. Acesso em: 20 abr. 2018.

CIAPRA BAIXO SUL. Sobre o CIAPRA. Disponível em: https://www.ciapra.ba.gov.br/consorcio. Acesso em: 30 nov. 2020.

COUTINHO, Adelaide Ferreira. Responsabilidade social do empresariado ou filantropia empresarial a serviço do capital? Revista Eletrônica Arma da Crítica, n. 4, 2012. Disponível em: <http://www.armadacritica.ufc.br/phocadownload/artigo9_20131.pdf>. Acesso em: 27 ago. 2020.

FREITAS, Luiz Carlos de. A reforma empresarial da educação: nova direita, velhas ideias. São Paulo: Expressão Popular, 2018.

GIDDENS, Antony. A Terceira Via. $4^{\text {a }}$ ed. Rio de Janeiro: Record, 1999.

ILHÉUS. Resolução CME n. 003, de 18 de dezembro de 2018. Define diretrizes para implantação da Reserva Técnica na Rede Pública Municipal de Ensino de llhéus alinhadas aos requisitos estabelecidos na Lei Federal (Lei do Piso) n ${ }^{\circ} 11.738$, de 16 de julho de 2008. Ilhéus, BA, 2018.

INSTITUTO NATURA. Trilhas. Disponível em: <http://www.institutonatura.org.br//iniciativa/trilhas/>. Acesso em: ago. 2017.

INSTITUTO UNIBANCO. Diálogos sobre a gestão municipal: Câmaras Técnicas de Consórcio. Disponível em: http://movimentocolabora.org.br/producao/. Acesso em: 15 ago. 2019.

LIMA, Kátia Regina de Souza; MARTINS, André Silva. Pressupostos, princípios e estratégias. In: NEVES, Lúcia Maria Wanderley (org.) A nova pedagogia da hegemonia: estratégias do capital para educar o consenso. São Paulo: Xamã, 2005.

MACEDO, Roseane Rodrigues. A garantia do direito à educação infantil na Unidade Acadêmica de Educação Infantil/UFCG a partir da Resolução CNE/CEB no. 1/2011 (2011-2016).2018. 156 p. Dissertação (Mestrado em Educação). Universidade Federal de Campina Grande, Centro de Humanidades, Campina Grande, 2018. Disponível em: <http://www.ppged.ufcg.edu.br/images/e/e5/DISSERTA\%C3\%87\%C3\%83O_ROSEANE_ RODRIGUES_DE_MACEDO.pdf>. Acesso em: 30 fev. 2019. 
MARTINS, André Silva. O Neoliberalismo da Terceira Via: uma proposta para educar a sociabilidade. In: MARTINS, André Silva. A direita para o social: a educação da sociabilidade no Brasil contemporâneo. Juiz de Fora: Editora UFJF, p. 59-110, 2009a.

MARTINS, André Silva. Burguesia e a nova sociabilidade: estratégias para educar o consenso no Brasil contemporâneo. 2006. 284 p. Tese (Doutorado em Educação). Universidade Federal Fluminense, Faculdade de Educação, Niterói-RJ, 2006.

MARTINS, André Silva. A educação básica no século XXI: o projeto do organismo 'Todos Pela Educação'. Práxis educativa, Ponta Grossa, v. 4, n. 1, p. 21-28, 2009b. Disponível em: <http://www.periodicos.uepg.brr>. Acesso em: 30 jul. 2017.

INSTITUTO NATURA. O Instituto. s. d., Disponível em: https://www.institutonatura.org/. Acesso em: 19 nov. 2020.

MEDEIROS, Islayne_Monalisa da Silva. A atuação do Instituto Natura na educação pública brasileira (2010-2014). 2015. 155 p. Dissertação (Mestrado em Educação) Universidade Federal da Paraíba, Centro de Educação, João Pessoa, 2015.

OLIVEIRA, Romualdo Portela de. A transformação da educação em mercadoria no Brasil. Educação \& Sociedade. Campinas, v. 30, n. 108, p. 739-760, out. 2009.

PERONI, Vera Maria Vidal. Implicações da relação público-privado para a democratização da educação no Brasil. In: PERONI, Vera (org.). Diálogos sobre definições no papel do Estado e nas fronteiras entre o público e o privado na educação. São Leopoldo: Oikos, 2015.

PIRES, Daniela Oliveira. O histórico da relação público-privado e a formação do Estado Nacional: implicações para a constituição da esfera pública. In: PERONI, Vera (org.). Diálogos sobre definições no papel do Estado e nas fronteiras entre o público e o privado na educação. São Leopoldo: Oikos, 2015.

PUTNAM, Robert D. Comunidade e democracia: a experiência da Itália Moderna. Rio de Janeiro: Fundação Getúlio Vargas, 1996.

ROSEMBERG, Fúlvia. Educação infantil brasileira contemporânea. 2003. Disponível em:

<http://www.diversidadeducainfantil.org.br/PDF/Educac\%C3\%A30\%20Infantil\%20Brasileir a\%20Contempor\%C3\%A2nea\%20-\%20F\%C3\%BAlvia\%20Rosemberg.pdf >. Acesso em: 10 dez. 2018.

SANTOS, Arlete Ramos dos; VIEIRA, Emilia Peixoto; SANTOS, Ivanei de Carvalho dos. O público e o privado na educação brasileira: um estudo de parcerias realizadas na Bahia. 2017. Revista O Público e o Privado. $n^{\circ} 30 \cdot$ jul/dez $\cdot 2017$ p. 61-88.

SUSIN, Maria OtiliaKroeff; MONTANO, Monique Robain. A educação Infantil no Brasil: direito de toda criança ainda em construção. In: PERONI, Vera (org). Diálogos sobre definições no papel do Estado e nas fronteiras entre o público e o privado na educação. São Leopoldo: Oikos, p.72-88, 2015. 